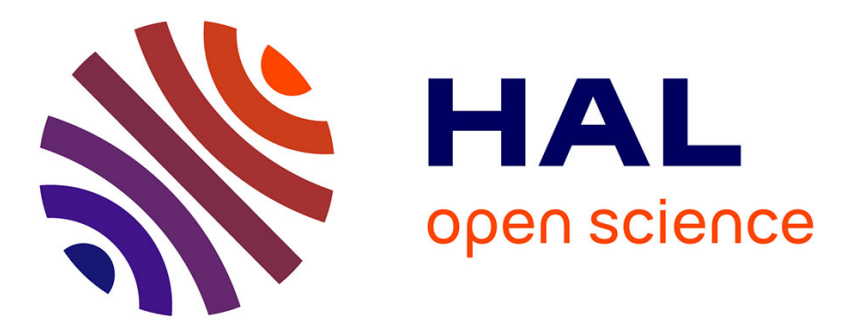

\title{
Impact of pump phase modulation on system performance of fibre-optical parametric amplifiers
}

\author{
A. Durécu-Legrand, Arnaud Mussot, C. Simonneau, D. Bayart, T. Sylvestre, \\ E. Lantz, H. Maillotte
}

\section{- To cite this version:}

A. Durécu-Legrand, Arnaud Mussot, C. Simonneau, D. Bayart, T. Sylvestre, et al.. Impact of pump phase modulation on system performance of fibre-optical parametric amplifiers. Electronics Letters, 2005, 41, nº 6, pp.83-84. hal-00097398

\section{HAL Id: hal-00097398 \\ https://hal.science/hal-00097398}

Submitted on 26 Aug 2013

HAL is a multi-disciplinary open access archive for the deposit and dissemination of scientific research documents, whether they are published or not. The documents may come from teaching and research institutions in France or abroad, or from public or private research centers.
L'archive ouverte pluridisciplinaire HAL, est destinée au dépôt et à la diffusion de documents scientifiques de niveau recherche, publiés ou non, émanant des établissements d'enseignement et de recherche français ou étrangers, des laboratoires publics ou privés. 


\section{Impact of pump phase modulation on system performance of fibre-optical parametric amplifiers}

A. Durécu-Legrand, A. Mussot, C. Simonneau, D. Bayart, T. Sylvestre, E. Lantz and H. Maillotte

Bit error rate induced in a parametric amplifier has been measured with a $10 \mathrm{Gbit} / \mathrm{s}$ line rate. It is shown experimentally that the phase modulation of the pump distorts the mark level of the channel and may cause system penalty. Different phase modulation schemes have been compared.

Introduction: Fibre-optical parametric amplifiers (FOPAs) have shown promising results in terms of both gain level [1] and amplification bandwidth [2]. But some challenges remain to realise practical FOPAs for optical telecommunications [3]. One of the main difficulties is raised by the stimulated Brillouin backscattering experienced by the continuous-wave pump. The phase modulation of the pump by a pseudorandom bit sequence (PRBS) is the most widespread solution to overcome this problem, even though an alternative modulation format based on sinusoids has been proposed [4]. Thanks to the phase modulation, the pump can propagate without backscattering in the nonlinear fibre and produce parametric gain. The level of gain is one of the essential characteristics of an FOPA but it is not the only one: channels must also be amplified without distortion. It is shown theoretically that, because of the phase-matching condition between the pump and the channel, the phase modulation of the pump may induce distortions [5]. In this Letter, we report bit error rate (BER) measurements that quantify the penalty for three different phase modulation formats and on the spectral amplification band.

Bit error rate measurements: To quantify the distortions of a parametrically amplified channel, BER measurements were carried out at the output of an FOPA. The architecture of the FOPA is similar to those of [6] and is constituted as follows. The pump is first phase modulated to increase the threshold of the stimulated Brillouin scattering. Then it is successively amplified by two EDFAs with a filtering of the ASE in between. A circulator and a reflective fibre Bragg grating were added to reduce the level of ASE from the EDFAs, as proposed in [7]. The pump $\lambda_{p}=1553.3 \mathrm{~nm}$ is injected into the fibre through a $90 / 10$ coupler, yielding a maximum launched power of $560 \mathrm{~mW}$. The amplifying fibre used in this FOPA is a highly nonlinear dispersion-shifted fibre $\left(L=490 \mathrm{~m}\right.$ and $\left.\lambda_{0}=1553 \mathrm{~nm}\right)$. The total fibre losses (attenuation + splicing losses) are $0.8 \mathrm{~dB}$. The signal can be tuned from 1555 to $1610 \mathrm{~nm}$. On the signal path, a polarisation controller allows the adjustment of the signal polarisation to maximise the gain and an isolator prevents occasional reflections $\left(P_{\text {sig }}=-20 \mathrm{dBm}\right)$. BER measurements were performed on a $10 \mathrm{Gbit} / \mathrm{s}$ NRZ modulated channel. The experimental setup is shown in Fig. 1. At the output of the FOPA, a circulator and a fibre Bragg grating, similar to those used in the FOPA, separate the amplification spectral band from the pump. The receiver is made up of an L-band preamplifier EDFA and an optical filter with a $3 \mathrm{~dB}$ bandwidth of $0.23 \mathrm{~nm}$ to reduce the ASE signal beat noise. BER is then plotted against the optical signal-to-noise ratio (OSNR), which is measured with the optical spectrum analyser OSA2, and for a constant optical power $(-11.3 \mathrm{dBm})$ to the photodiode. By means of a variable attenuator Att1 placed before the preamplifier, the OSNR can be decreased in front of the receiver to achieve measurable BERs. Backto-back measurements are realised by connecting point $\mathrm{A}$ to point $\mathrm{B}$. Finally the on/off parametric gain of the FOPA is measured on OSA1.

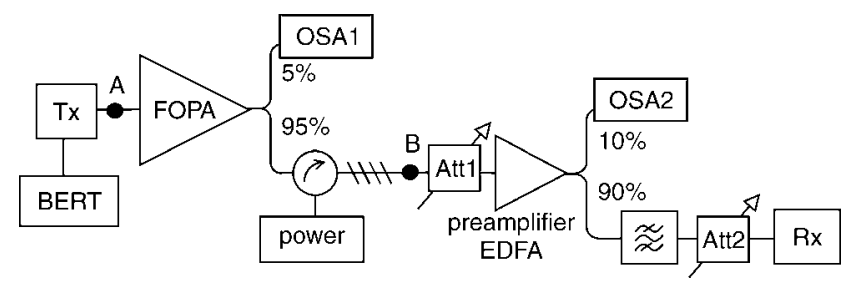

Fig. 1 Experimental setup for BER measurements
Experimental results and discussions: BERs were first measured in a back-to-back configuration, then with the FOPA by applying different modulation formats to the pump phase. Three different formats were tested: first a PRBS of $3.5 \mathrm{Gbit} / \mathrm{s}$, with a word length of $2^{7}-1$, which modulates the pump phase between 0 and $\pi$, then the same PRBS, filtered by an electrical filter with a $3 \mathrm{~dB}$ bandwidth of $3.04 \mathrm{GHz}$ and finally a combination of four sinusoidal signals $\left(f_{1}=120 \mathrm{MHz}\right.$, $f_{2}=532 \mathrm{MHz}, f_{3}=942 \mathrm{MHz}$ and $f_{4}=1.81 \mathrm{GHz}$ ). The electrical filtering of the PRBS enables an increase of the risetime of the phase bits from 100 to $150 \mathrm{ps}$. In the case of the sinusoid modulation format, a rather low Brillouin threshold of $300 \mathrm{~mW}$ was achieved. To compare the impact of the different modulation formats, BERs were measured in the same pumping conditions $\left(P_{p}=280 \mathrm{~mW}\right)$ and for the same channel wavelength $1595 \mathrm{~nm}$ (about $42 \mathrm{~nm}$ from the pump), which corresponds to a maximum on/off gain of $6.7 \mathrm{~dB}$. The results of BER measurements are shown in Fig. 2. The impact of the pump phase modulation on the performance of the FOPA can be clearly observed in terms of OSNR penalty, i.e. increase of the OSNR to achieve the same BER as in the back-to-back configuration. The OSNR penalty for a bit error rate of $10^{-9}$ is $1.38 \mathrm{~dB}$ for the PRBS (18.9-17.52), $0.91 \mathrm{~dB}$ for the filtered PRBS and $0.59 \mathrm{~dB}$ for the combination of sinusoids. First the increase in the risetime of the PRBS phase bits with the electrical filter leads to a reduction of the penalty by $0.47 \mathrm{~dB}$. Then for the combination of four sinusoids, the pump phase experiences analogical continuous variations so that the modifications of the phase-matching conditions are not so large. Consequently the penalty is further reduced by $0.32 \mathrm{~dB}$. As all measurements were performed under the same operating conditions except for the phase modulation formats, this experiment points out the distortions induced by the pump phase modulation. BER measurements were also performed with another channel wavelength at $1560 \mathrm{~nm}$, i.e. near the pump wavelength, and with the three different modulation formats. The results, which are not presented here for the sake of clarity, reveal that the channel experiences no OSNR penalty. BER measurements are identical to the back-to-back one, even in the case of the unfiltered PRBS format.

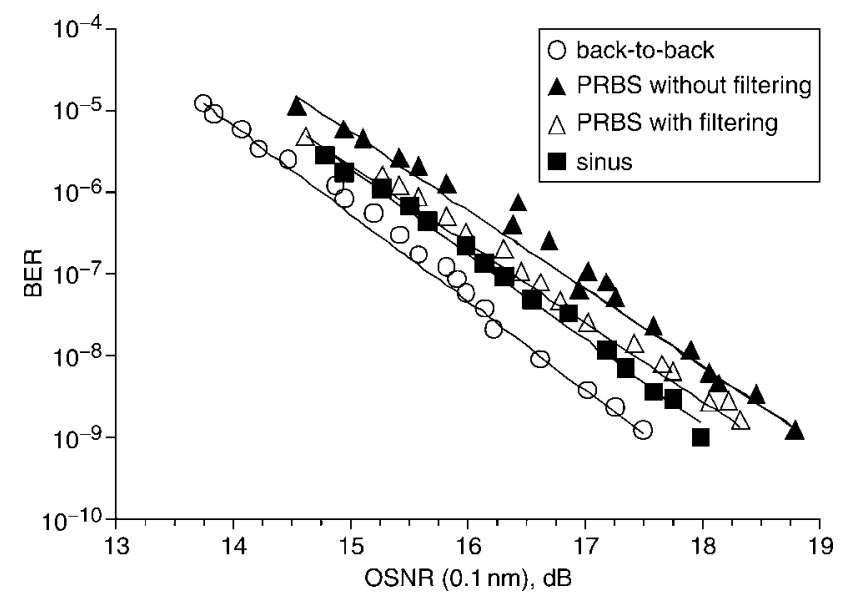

Fig. 2 OSNR penalty induced by three different modulation formats of pump phase

$P_{p}=280 \mathrm{~mW}, \lambda$ channel $=1595 \mathrm{~nm}$

To demonstrate further the impact of this phenomenon on system performance, another set of BER measurements was realised for different wavelengths and with a higher pump power $\left(P_{p}=330 \mathrm{~mW}\right)$ so as to get the gain spectrum a bit more spiky than previously. PRBS phase modulation with electrical filtering was used. Three channel wavelengths were chosen: $\lambda=1575,1585$ and $1595 \mathrm{~nm} .1585 \mathrm{~nm}$ is the wavelength located at the inflexion point of the gain curve and $1595 \mathrm{~nm}$ is the wavelength at the maximum of gain $10 \mathrm{~dB}$ (inset of Fig. 3). Experimental results are presented in Fig. 3. The lowest penalty, $1 \mathrm{~dB}$, is obtained for the channel $1575 \mathrm{~nm}$, the closest to the pump, and the worst penalty $3.7 \mathrm{~dB}$ for the channel $1585 \mathrm{~nm}$ located at the inflexion point of the gain curve. The channel at the maximum gain has an intermediate penalty $2.4 \mathrm{~dB}$. This evolution of the penalty on the spectral amplification band is one of the characteristics of distortions caused by the pump phase modulation [5]. It demonstrates that the 
major part of the measured penalty comes from the phase modulation and not from any other perturbations, e.g. transfer on the channel of the pump RIN. In the RIN transfer case, the penalty would have been maximum at the maximum of gain.

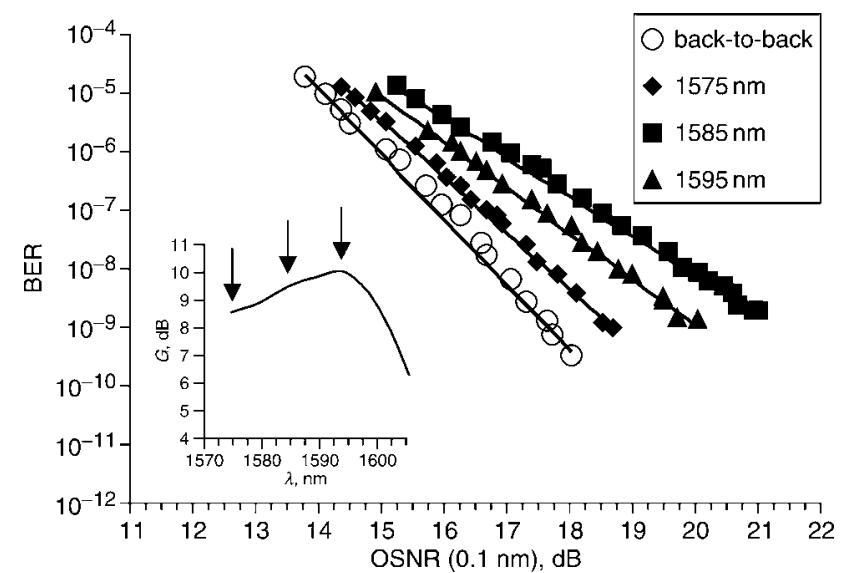

Fig. 3 Evolution of OSNR penalty of FOPA on amplification band for filtered PRBS modulation of pump phase

Inset: Measured gain spectrum of FOPA with $P_{p}=330 \mathrm{~mW}$

Conclusions: The OSNR penalty of a fibre-optical parametric amplifier has been quantified through BER measurements with a $10 \mathrm{Gbit} / \mathrm{s}$ line rate. By comparing three phase modulation formats, we have shown that, apart from the efficiency of the pump phase modulation to avoid the Brillouin effect, attention should be paid to the associated extra penalty experienced by the channels. By comparing three phase modulation schemes, we have shown that smoothing the variations of the pump phase reduces the penalty: the lowest penalty of $0.59 \mathrm{~dB}$ was achieved with a phase modulation format constituted by four sinusoids. The influence of the pump phase modulation was also evidenced by the dependence of the penalty on the channel wavelength.

(C) IEE 2005

4 November 2004
A. Durécu-Legrand, C. Simonneau and D. Bayart (Alcatel, Research and Innovation Department, Route de Nozay, F-91460 Marcoussis, France)

E-mail: anne.durecu@alcatel.fr.

A. Mussot, T. Sylvestre, E. Lantz and H. Maillotte (Département d'Optique P. M. Duffieux, Institut FEMTO-ST, UMR CNRS/Université de Franche-Comté 6174, F-25030 Besançon cedex, France)

\section{References}

1 Hansryd, J., and Andrekson, P.A.: 'Broadband CW pumped fibre optical parametric amplifier with $49 \mathrm{~dB}$ gain and wavelength conversion efficiency'. Proc. OFC 2000, Paper PD 3

2 Ho, M.-C., Marhic, M.E., Akasaka, Y., and Kasovsky, L.G.: 'Fibre optical parametric amplifier and wavelength converter with 208-nm gain bandwidth'. Proc. CLEO 2000, Paper CThC6, pp. 401-402

3 Marhic, M.: 'Toward practical fibre optical parametric amplifiers'. Proc. OFC 2003, Paper ThT3, pp. 10-11

4 Korotky, S.K., Hasen, P.B., Eskildsen, L., and Veselka, J.J.: 'Efficient phase modulation scheme for suppressing stimulated Brillouin scattering'. Tech. Dig. Int. Conf. IOOC, 1995, Vol. 2, pp. 110-111

5 Mussot, A., Durécu-Legrand, A., Lantz, E., Simonneau, C., Bayart, D., Maillotte, H., and Sylvestre, T.: 'Impact of pump phase modulation on the gain of fibre optical parametric amplifier', IEEE Photonics Technol. Lett., 2004, 16, pp. 1289-1291

6 Legrand, A., Simonneau, C., Bayart, D., Mussot, A., Lantz, E., Sylvestre, T., and Maillotte, H.: 'Impact of the longitudinal variations of the chromatic dispersion on the gain of fibre parametric amplifiers'. Optical Amplifiers and their Applications, OSA Top. Mtg, 2003, Paper We2

7 Blows, J.L., and French, S.E.: 'Low-noise-figure parametric amplifier with a continuous-wave frequency-modulated pump', Opt. Lett., 2002, 27, pp. 491-493 